\title{
Hyoscyamine Sulfate
}

National Cancer Institute

\section{Source}

National Cancer Institute. Hyoscyamine Sulfate. NCI Thesaurus. Code C74575.

The sulfate salt of a belladonna alkaloid derivative and the levorotatory form of racemic atropine isolated from the plants Hyoscyamus niger or Atropa belladonna, which exhibits anticholinergic activity. Hyoscyamine functions as a non-selective, competitive antagonist of muscarinic receptors, thereby inhibiting the parasympathetic activities of acetylcholine on the salivary, bronchial, and sweat glands, as well as the eye, heart, bladder, and gastrointestinal tract. These inhibitory effects cause a decrease in saliva, bronchial mucus, gastric juices, and sweat. Furthermore, its inhibitory action on smooth muscle prevents bladder contraction and decreases gastrointestinal motility. 